\title{
Does Endometrial Injury Guided Hysteroscopy Improve Implantation Rate of Frozen-Thawed Embryo Transfer?
}

\author{
Author \\ Ashraf Hany Abdelrahman \\ Department of Obstetrics \& Gynecology (Shatby IVF-ICSI Unit) Alexandria University, Egypt \\ Madina IVF-ICSI Center Alexandria, EGYPT \\ 416 El Horria Road, Roushdy Alexandria, Egypt \\ Email: ashrafhany3000@yahoo.com
}

\begin{abstract}
Implantation failure is one of the most important factors limiting success in IVF-ICSI treatment. The majority of trials have demonstrated favorable effect of endometrial injury on implantation success rate especially in women who failed to implant before, on the other hand some studies failed to find a beneficial response.
\end{abstract}

0bjective: The purpose of our trial was to explore whether endometrial injury guided hysteroscopy in a cycle (luteal phase) prior to frozen-thawed (FT) blastocyst transfer cycles would improve implantation rate. Materials and Methods: We conducted a prospective randomized controlled trial of 90 consecutive women at Shatby IVF-ICSI unit at the university hospital and Madina IVF-ICSI center. All women were undergone frozen-thawed (FT) blastocyst transfer cycles. Women in the test group underwent endometrial injury guided hysteroscopy in the cycle (luteal phase) preceding FT blastocyst transfer cycle. Primary outcomes were implantation and chemical pregnancy rates.

Results: 45 subjects who underwent endometrial injury (EI) guided hysteroscopy were compared with 45 control group which did not include any uterine manipulation. There were no significant differences in baseline and cycle characteristics between two groups. Chemical (57.8\% versus $31.1 \%)$ and implantation $(42.2 \%$ versus $15.6 \%)$, rates were significantly higher in the test group compared to the control group

Conclusion: Based on results ofthis study, local injury to endometrium guided hysteroscopy in the cycle preceded the FT blastocyst transfer cycle had promising results on implantation and pregnancy rates.

Keywords: Endometrial injury, Frozen-thawed blastocyst transfer, Implantation rat.

\section{INTRODUCTION}

Implantation of the embryo, which is a requirement for successful pregnancy, can only take place in a receptive uterus. In humans, the uterus becomes receptive during the mid-secretory phase of the menstrual cycle (days 19 to 23), commonly known as the window of implantation (WOI). It is assumed that inadequate uterine receptivity is responsible for approximately two-thirds of implantation failures [1\}. Although many fertility disorders have been overcome by a variety of assisted reproductive techniques, implantation remains the rate-limiting step for the success of in vitro fertilization (IVF). Implantation of embryo is a multiple process including several cytokines and growth factors, along with a dialogue between embryo and uterine 
endometrium ${ }^{[2]}$. Multiple factors have been contributed increasing embryo implantation success [3]. Majority of trials have demonstrated favourable effect of endometrial injury on implantation success rate, especially in women with recurrent implantation failure (RIF), while some studies failed to detect any benefit ${ }^{[4-12]}$.

Kalma et al suggested that "local injury to endometrium causes significant changes in pattern of expression of genes related to implantation" [13] Gnainsky et al reported that "endometrial injury induces an inflammatory reaction which favours implantation" ${ }^{[14]}$. Dendritic cells, natural killer cells and macrophages are employed to local injury and increased amounts of cytokines, chemokines and growth factors are secreted, thus resulting in successful implantation ${ }^{[14,15]}$.

So, there has not been enough research due to the effectiveness of endometrial injury prior to frozenthawed (FT) blastocyst transfer cycle.

The objective of this RCT was to test the hypothesis that endometrial injury guided hysteroscopy in the nontransfer cycle could improve the probability of pregnancy in the subsequent IVF- FT blastocyst transfer cycle in patients who had previous failed IVF outcome.

\section{MATERIAL AND METHODS}

This randomized clinical trial conducted at Shatby university hospital (Infertility Unit) and Madina IVF-ICSI centre both at Alexandria city in Egypt, between July 2015 to June 2016. The study was approved by the medical ethics committee and informed consents were obtained from all participants involved in the study. All procedures followed were in accordance with the ethical standards of the responsible committee on human experimentation (institutional and national) and with the Helsinki Declaration of 1975, as revised in 2008

\section{Study Design and Participants:}

For study population a computer-generated randomization table was created.
The inclusion criteria include: women indicated for FT blastocyst transfer treatment, had one or more frozen embryo(s) and had a normal uterine cavity (confirmed by vaginal ultrasonography). The exclusion criteria were women with history of endocrine disorders (hypothyroidism, diabetes mellitus), intrauterine abnormality (uterine polyp, sub-mucosal fibroma, intrauterine adhesion) and severe endometriosis diagnosed by laparoscopy or endometrioma in ultrasound scanning.

This study included 90 participants. We allocated the participants in two groups: endometrial injury (EI) group guided hysteroscopy or test group $(n=45)$ and non-intervention group or control group $(n=45)$. In the EI group, women underwent endometrial injury during the luteal phase of the preceding menstrual cycle of FT blastocyst transfer. EI was performed guided hysteroscopy using the right angle at lateral walls (blunt injury) of the endometrial cavity. In the subsequent cycle, all of women underwent our standard endometrial preparation protocol for frozen thawed embryo transfer (FET) cycles with estradiol valerate $6 \mathrm{mg}$ daily from day 2 of the cycle.A transvaginal ultrasound was then performed around day 10 of cycle and if endometrial thickness was $\geq 8 \mathrm{~mm}$ with a triple-line appearance, subject was started on vaginal progesterone pessary $800 \mathrm{mg}$ daily (Actavis, UK) and embryo transfer was performed 5 days later with expanded blastocyst frozen-thawed embryos with Cook Catheter (USA).

\section{Outcome measures}

The primary outcomes were chemical pregnancy and implantation and miscarriage rates. Chemical pregnancy rate was defined as positive B- HCG test 14 days after embryo transfer. Implantation rate was the sacs number seen on transvaginal ultrasound scan divided by the number of transferred embryos. Miscarriage rate was defined as miscarriages number before 20 weeks

\section{Statistical analysis}

MaxStat Pro (Statistical Package for the Social Sciences Version 3.60 software copy right 2015, 
USA) was used for all statistical calculations. Student's t-test was used for comparing quantitative variables and ${ }^{2}$ test used to compare categorical data. $P$ value $<0.05$ is considered statistically significant.

\section{RESULTS}

In total, 90 women who underwent FET treatment were analysed. Women were divided into two groups: EI guided hysteroscopy $(n=45)$ and non EI group which did not include any uterine manipulation in preceding cycle $(n=45)$. Baseline characteristics between two groups (age of the patients and duration of infertility) were comparable with no significant difference as shown in Table 1. Also the stimulation days using oestradiol valerate for endometrial preparation were equal between the two groups together with the endometrial thickness on progesterone initiation day as also clearly demonstrated in table 1.Chemical pregnancy outcome was significantly higher in the EI guided hysteroscopy $57.8 \%$ versus $31.1 \%$ in the nonintervention group. Implantation rate was increased significantly in EI (42.2\%) compared with non EI group $(15.6 \%)$, and finally although miscarriage rate tends to be higher in the non-intervention group but it did not reach significant difference $(11.1 \%$ vs. $8.9 \%$ )

\section{DISCUSSION}

The role of endometrial injury in IVF was controversial. Barash et al first demonstrated that EI during the cycle preceding IVF doubled the implantation rates, clinical pregnancy, and live birth rates in women with RIF ${ }^{[4]}$. Several studies confirmed the positive effect of EI on embryo implantation and clinical pregnancies at different time and with different frequencies, however, conflicting results were reported ${ }^{[5,6]}$. Yeung et al demonstrated that EI performed in luteal phase of preceding cycle does not improve the ongoing pregnancy rate in unselected sub fertile women undergoing IVF ${ }^{[8]}$. Therefore, population, timing, technique and frequencies of endometrial injury were variable and led to different outcomes. In the present study, chemical pregnancy rate significantly increased at the EI group or test group when compared to the non-intervention group $(57.8 \%$ versus $31.1 \%$ ). In addition a higher implantation rate was clearly evident at the intervention group as compared to the control group with a significant $\mathrm{P}$ value of 0.0376 . Even though the miscarriage rate was lower at the test group, the $\mathrm{P}$ value did not reach significants $(P=0.4041)$. So our results are compatible with the following series of events. Local injury of endometrium promotes an inflammatory response as reported previously ${ }^{[16]}$. Proinflammatory cytokines such as TNF- $\alpha$, produced by the wounded endometrium, stimulate the secretion of other chemokines/cytokines which, in turn, recruit macrophages/DCs to the site of implantation. These immune cells enhance the inflammatory reaction and may trigger the uterine epithelium to produce molecules that interact with the blastocyst, enhance decidualization and facilitate implantation for a few cycles ${ }^{[10-15]}$. It has also been demonstrated that endometrial injury up-regulates the gene expression related to endometrial receptivity which optimizes endometrial development ${ }^{[15,17-}$ ${ }^{18]}$. Based on the strong correlation of pregnancy outcome with the increase in the abundance of macrophages/DCs and cytokine expression, so we suggest that endometrial injury guided hysteroscopy may also induce inflammation that facilitate the preparation of a receptive endometrium in IVF patients who failed to implant before in stimulated cycle. To our knowledge, no study has demonstrated the effectiveness of endometrial injury guided hysteroscopy in a cycle preceding transferring frozen-thawed blastocyst. 


\section{JMSCR Vol||04||Issue||12||Page 15031-15035||December}

Table 1

\begin{tabular}{|c|c|c|c|}
\hline & $\begin{array}{c}\text { Endometrial } \\
\text { injury guided } \\
\text { hysteroscopy } \\
\text { Or test group } \\
(n=45) \\
\text { Mean } \pm \text { SD }\end{array}$ & $\begin{array}{l}\text { Control patients with } \\
\text { no intervention Or } \\
\text { control group } \\
(\mathrm{n}=45) \\
\text { Mean } \pm \text { SD }\end{array}$ & $P$ value \\
\hline Age of patient in years & $28.5 \pm 3.5$ & $29.2 \pm 3.2$ & 0.3725 \\
\hline $\begin{array}{l}\text { Duration of infertility in } \\
\text { years }\end{array}$ & $5.98 \pm 1.18$ & $5.71 \pm 1.14$ & 0.2977 \\
\hline $\begin{array}{l}\text { Number of stimulation } \\
\text { days }\end{array}$ & $12.51 \pm 0.79$ & $12.38 \pm 0.75$ & 0.3604 \\
\hline $\begin{array}{l}\text { Endometrium thickness } \\
\text { at the day of HCG in } \\
\mathrm{mm}\end{array}$ & $10.1 \pm 1.0$ & $10.1 \pm 0.9$ & 0.9575 \\
\hline $\begin{array}{l}\text { Number. Of transferred } \\
\text { embryos at day } 5\end{array}$ & $1.7 \pm 0.5$ & $1.6 \pm 0.5$ & 0.3751 \\
\hline $\begin{array}{lcl}\% & \text { Of } & \text { Chemical } \\
\text { pregnancy } & \\
\end{array}$ & 57.8 & 31.1 & 0.0216 \\
\hline $\begin{array}{l}\% \text { Of Implantation } \\
\text { rate }\end{array}$ & 42.2 & 15.6 & 0.0376 \\
\hline$\%$ Of Miscarriage rate & 8.9 & 11.1 & 0.4041 \\
\hline
\end{tabular}

$\mathrm{P}$ value $<0.05$ is considered statistically significant.

\section{CONCLUSION}

The results of this study suggest that endometrial response to guided hysteroscopic injury in the cycle preceding the FT blastocyst transfer might be a promising intervention in the future for those with implantation failure in stimulated ICSI cycle before, and somore randomized control trials with large sample size of patients are needed in order to confirm this preliminary data.

\section{ACKNOWLEDGMENT}

The authors thank Madina IVF-ICSI Lab Team and Shatby IVF-ICSI Team, for there valuable Lab support. Prof Fayek for statistical assistance

\section{REFERENCES}

1. Simon C, Moreno C, Remohi J, Pellicer A. Molecular interactions between embryo and uterus in the adhesion phase of human implantation. Hum Reprod. 1998;13(Suppl 3):219-32.

2. Gibreel A, Badawy A, ElfRefai W, ElfAdawi N. Endometrial scratching to improve pregnancy rate in couples with unexplained subfertility: a randomized controlled trial. J ObstetGynaecol Res. 2013; 39:680-684.

3. Shohayeb A, El-Khayat W. Does a single endometrial biopsy regimen (S-EBR) improve ICSI outcome in patients with repeated implantation failure? A randomised controlled trial. Eur J ObstetGynecolReprod Biol. 2012;164:176-179.

4. Barash A, Dekel N, Fieldust S, Segal I, Schechtman E, Granot I. Local injury to the endometrium doubles the incidence of successful pregnancies in patients undergoing in vitro fertilization. FertilSteril. 2003; 79:1317-1322.

5. Narvekar SA, Gupta N, Shetty N, Kottur A, Srinivas M, Rao KA. Does local endometrial injury in the nontransfer cycle improve the IVF-ET outcome in the subsequent cycle in patients with previous unsuccessful IVF? A randomized controlled pilot study. J Hum Reprod Sci. 2010; 3:15-19.

6. Tiboni GM, Giampietro F, Gabriele E, Di Donato V, Impicciatore GG. Impact of a single endometrial injury on assisted reproductive technology outcome: a preliminary observational study. J Reprod Med. 2011;56:504-506.

7. Karimzade MA, Oskouian H, Ahmadi S, Oskouian L. Local injury to the endometrium on the day of oocyte retrieval has a negative impact on implantation in assisted reproductive cycles: a randomized controlled trial. Arch Gynecol Obstet. 2010; 281:499-503.

8. Yeung TW, Chai J, Li RH, Lee VC, Ho PC, $\mathrm{Ng} \mathrm{EH}$. The effect of endometrial injury on ongoing pregnancy rate in unselected subfertile women undergoing in vitro fertilization: a randomized controlled trial. Hum Reprod. 2014; 29:2474-2481.

9. Dekel N, Gnainsky Y, Granot I, Mor G. Review article: Inflammation and implantation. Am J ReprodImmunol. 2010; 63:17-21. 
10. Finn C, Martin L. Endocrine control of the timing of endometrial sensitivity to a decidual stimulus. Biol Reprod. 1972;7:82-86.

11. Sharkey A. Cytokines and implantation. Rev Reprod. 1998;3:52-61.

12. Akita S, Ishihara H, Abdur RM, Fujii T. Leukemia inhibitory factor gene improves skin allograft survival in the mouse model1. Transplantation. 2000; 70:10261031.

13. Basak S, Dubanchet S, Zourbas S, Chaouat G, Das C. Expression of Pro-inflammatory Cytokines in Mouse Blastocysts During Implantation: Modulation by Steroid Hormones. Am J Reprod Immunol.2002;47:2-11.

14. Schlitzer A, McGovern N, Ginhoux F. Dendritic cells and monocyte-derived cells: Two complementary and integrated functional systems. Semin Cell Dev Biol. 2015;41:9-22.

15. Kalma Y, Granot I, Gnainsky Y, Or Y, Czernobilsky B, Dekel N, et al. Endometrial biopsy-induced gene modulation: first evidence for the expression of bladdertransmembranaluroplakinIb in human endometrium. FertilSteril. 2009; 91:10421049.

16. YuliaGnainsky, IritGranot, Paulomi B. Aldo, AmihaiBarash, Yuval Or, Edna Schechtman, Gil Mor, and Nava Dekel. Local injury of the endometrium induces an inflammatory response that promotes successful implantation. FertilSteril. 2010 Nov; 94(6): 2030-2036.

17. Almog B, Shalom-Paz E, Dufort D, Tulandi T. Promoting implantation by local injury to the endometrium. FertilSteril. 2010; 94: 2026-2029.

18. Gnainsky Y, Granot I, Aldo P, Barash A, Or $\mathrm{Y}$, Mor G, et al. Biopsy-induced inflammatory conditions improve endometrial receptivity: the mechanism of action. Reproduction. 2015; 149:75-85. 